\title{
Photochemical [2+1]-Cycloadditions of Nucleophilic Carbenes
}

\author{
Amanda Bunyamin ${ }^{a}$, Anastasios Polyzos, ${ }^{a, b}$ Daniel L. Priebbenow ${ }^{* a, c}$
}

\begin{abstract}
Visible light induced singlet nucleophilic carbene intermediates undergo rapid [2+1]-cycloaddition with tethered olefins to afford unique bicyclo[3.1.0]hexane and bicyclo[4.1.0]heptane scaffolds. This cyclopropanation proceeds using only visible light irradiation, circumventing the use of exogenous (photo)catalysts or sensitisers and showcases an underexplored mode of reactivity for nucleophilic carbenes in chemical synthesis. The discovery of additional transformations including a cyclopropanation/retro-Michael/Michael cascade reaction to afford chromanone derivatives are also described.
\end{abstract}

Cyclopropane derivatives including donor-acceptor cyclopropanes and cyclopropanols are valuable building blocks in chemical synthesis. ${ }^{1}$ Cyclopropanes are also widely prevalent in natural products (e.g. Peyssonnoside A), ${ }^{2}$ and medicinal chemistry settings, ${ }^{3}$ exemplified by the potent indoleamine 2,3-dioxygenase 1 (IDO1) inhibitor (Figure 1) reported by Hamilton and co-workers who highlighted the significant advantages that conformationally constrained bicyclo[3.1.0]hexane scaffolds offered in terms of improving metabolic stability and limiting off-target effects when used as a cyclohexane isostere. ${ }^{4}$

Common strategies to construct cyclopropanes include the JohnsonCorey-Chaykovsky or Simmons-Smith reaction. ${ }^{5}$ The most widely employed cyclopropanation strategy in chemical synthesis remains the $[2+1]$-cycloaddition of olefins with carbene intermediates. ${ }^{6}$ The most fundamental of all cycloaddition processes, this cyclopropanation reaction typically involves reaction of olefins with electrophilic carbene (or carbenoid) intermediates generated from diazo or hydrazone reagents using rhodium, iron, copper, cobalt, and boron catalysts. ${ }^{\text {? }}$

In recent years, more economic and sustainable synthetic methods have been developed employing visible light irradiation to directly generate reactive intermediates in the absence of photocatalysts or photosensitisers. ${ }^{8}$ Within this context, in 2019, Suero reported the cyclopropanation of styrenes via the visible light induced generation of iodomethyl carbonyl radicals. ${ }^{9}$

Catalyst-free visible light mediated cyclopropanation strategies have also been developed by the Königs group, who recently demonstrated that electrophilic carbene intermediates generated photochemically from donor-acceptor diazoalkanes or tosyl hydrazones undergo $[2+1]$ cycloaddition with unsaturated cyclooctatetraenes, carbocycles and heterocycles..$^{10} \mathrm{~A}$ limitation however, for many of the metal-catalysed and photochemical cyclopropanation reactions developed to date is the common use of relatively toxic diazo reagents that typically require the presence of stabilizing electron-withdrawing groups.

Singlet nucleophilic carbene (SNC) intermediates can be generated photochemically, as exemplified by siloxy carbenes which are readily accessible from bench-stable acyl silanes via visible light irradiation (370$420 \mathrm{~nm}) .{ }^{11}$ Thus, we questioned whether new photochemical cyclopropanation strategies might be accessible exploiting the $[2+1]$ cycloaddition of visible light induced nucleophilic carbenes with olefins.

\footnotetext{
a A. Bunyamin, Dr. A. Polyzos, Dr. D. L. Priebbenow

School of Chemistry, Faculty of Science

University of Melbourne, Parkville, Victoria, 3010 (Australia).

E-mail: daniel.priebbenow@unimelb.edu.au

$b$ Dr A. Polyzos

CSIRO Manufacturing

Research Way, Clayton, Victoria, 3168 (Australia)

c Dr. D. L. Priebbenow

Department of Medicinal Chemistry, Monash Institute of Pharmaceutical Science,
} Monash University, Parkville, Victoria, 3052 (Australia)

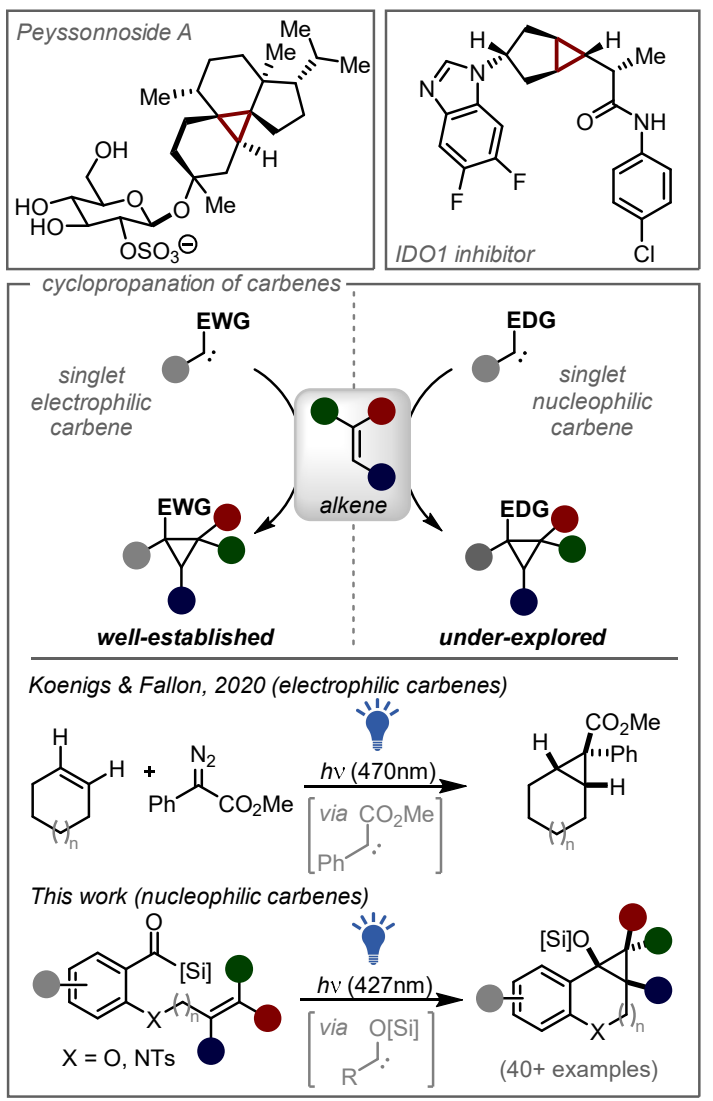

Figure 1. Compared to electrophilic singlet carbenes, the [2+1]-cycloaddition reaction of olefins with nucleophilic carbenes are vastly underexplored.

To date, only two solitary examples describing the [2+1]photocycloaddition of nucleophilic carbenes exist (both involving reaction with diethyl fumarate as reported by Brook in 1971 and Dalton in 1981). ${ }^{12}$ Relative to electrophilic carbenes the cyclopropanation of nucleophilic carbenes has been seldom reported. ${ }^{12-13}$ We herein report our discovery that visible light induced nucleophilic carbene intermediates undergo rapid and highly stereospecific [2+1]cycloadditions with olefins including styrene, acrylamide, and vinyl phosphonate derivatives. This photochemical cyclopropanation process affords unique siloxy-derived bicyclo[3.1.0]hexane and bicyclo[4.1.0]heptane scaffolds, and showcases a significantly underexplored mode of reactivity for nucleophilic carbenes.

To begin our investigations, we explored the reaction of phenethyl acyl silane 1a with olefins including styrene, ethyl acrylate, and dimethyl fumarate using visible light irradiation at $427 \mathrm{~nm}$. As the dominant orbital 
interaction that drives the $[2+1]$-cycloaddition of olefins with nucleophilic carbenes is between the filled carbene $\mathrm{sp}^{2}$-orbital $\left(\mathrm{HOMO}_{\text {carbene }}\right)$ with the $\mathrm{LUMO}_{\text {alkene, }}{ }^{14}$ the only olefin sufficiently activated enough to undergo cyclopropanation was the fumarate containing two electron withdrawing groups, to yield trans-cyclopropane 2 in $84 \%$ yield. ${ }^{15}$

In an attempt to increase reactivity, we next employed an intramolecular approach and were able to demonstrate for the first time that the $[2+1]$-photocycloaddition of nucleophilic carbenes proceeded efficiently for olefins other than fumarates. This was achieved via irradiation of acrylate derivative 3 ( $427 \mathrm{~nm}$ LED, 40W) which produced bicyclo[3.1.0]hexane 4 with exclusive formation of the exo-isomer (Scheme 1).
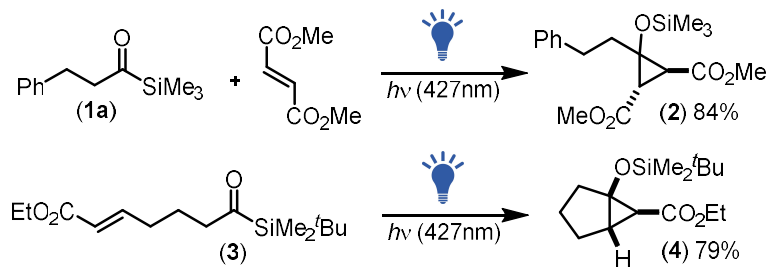

Scheme 1. Carbenes generated from alkyl acyl silanes readily participated in both inter- and intramolecular photochemical $[2+1]$-cycloaddition processes.

Building on this outcome, we considered that phenol or aniline derived aroyl silanes would enable in-depth investigations into this cyclopropanation process via rapid variation of the olefin tether from a common starting material. To this end, we prepared a series of sulfonamide derived acyl silanes 1 using an $\operatorname{Ir}(\mathrm{III})$-catalysed sulfonamidation of benzoyl silanes with tosylazide. ${ }^{11 \mathrm{~d}}$ Subsequent DABCO catalysed addition of the tosylamide motif to methyl propiolate produced acyl silanes (7) containing an electron-deficient olefin. ${ }^{16}$

Exposure of a solution of aroyl silane $7 \mathrm{a}$ in diethyl ether to visible light irradiation ( $427 \mathrm{~nm} \mathrm{LED}, 40 \mathrm{~W}$ ) led to a colour change from bright yellow to colourless after only 10 minutes to afford tert-butyldimethylsiloxy azabicyclo[3.1.0] hexane (9a), readily identified by ${ }^{1} \mathrm{H}$ NMR analysis from the distinctive cyclopropane $\mathrm{C}-\mathrm{H}$ resonances at $\delta=4.71 \mathrm{ppm}$ and $\delta=0.82 \mathrm{ppm}(J=2.6 \mathrm{~Hz})$. X-ray crystallography of $9 \mathrm{a}(\mathrm{CCDC} 2121946)$ confirmed the structure (Scheme 2a), with the exo-isomer formed as the major isomer as indicated by both NMR and X-ray analysis. Optimisation of the reaction conditions confirmed that several solvents were suitable, however diethyl ether remained the preferred choice. ${ }^{17}$

Subsequently, ortho-sulfonamido derived acyl silanes 1 were reacted with various propiolates to afford acyl silanes (7) containing olefin tethers. Visible light irradiation of these substrates (427 nm LED, 40W) produced a series of azabicyclo[3.1.0]hexanes (9a-9i, Scheme 2a). In each case, the exo diastereoisomer was produced as the sole diastereoisomer, with variations in the silyl, aryl, and ester functional groups well tolerated. Advantageously, this cyclopropanation is complete in less than 10 minutes and is operationally simple, requiring only visible light irradiation, circumventing the use of exogenous catalysts, or additives including photosensitisers.

To further probe the $[2+1]$-photocycloaddition, we set out to vary the heteroatom and extend the tether length to investigate if bicyclo[4.1.0] heptane frameworks were also accessible. To achieve this, we employed salicylaldehyde derived acyl silanes that were $O$-alkylated via reaction with various bromocrotonate derivatives. Subsequent irradiation of the functionalised acyl silanes (8) with visible light $(427 \mathrm{~nm}$ LED, 40W) afforded oxabicyclo[4.1.0]heptane scaffolds (10a-10k, Scheme $2 b$ ) with variation in the structure of both the crotonate ester group and benzoyl silane well tolerated. The oxabicyclo[4.1.0]heptane products were readily identified by ${ }^{1} \mathrm{H}$ NMR analysis from the distinctive cyclopropane $\mathrm{C}-\mathrm{H}$ resonances at $\delta=2.60 \mathrm{ppm}$ and $\delta=2.20 \mathrm{ppm}(J=$ $5.8 \mathrm{~Hz}$ ). X-ray crystallographic analysis of 10k (CCDC 212194) confirmed the structure and exo-configuration.

With the reaction performing exceptionally well for ester derived electron deficient alkenes, we next explored the influence of alternative alkene substituents on the success of the reaction. Neutral alkenes situated within allyl, methyl allyl and dimethyl allyl tethers all underwent photochemical cyclopropanation reaction with visible light induced nucleophilic carbenes, however these less activated alkenes required reaction times of up to 2 hours to achieve complete conversion (Scheme $2 \mathrm{~b}, 101-10 \mathrm{n}, 70-82 \%)$. The orbital interaction required to drive $[2+1]$ cycloaddition for these less activated alkenes is that between the filled alkene p-orbital $\left(\mathrm{HOMO}_{\text {alkene }}\right)$ and the vacant carbene 2 p-orbital $\left(\mathrm{LUMO}_{\text {carbene }}\right)$. Thus, the fact that these relatively electron-rich alkenes undergo cycloaddition with nucleophilic siloxy carbenes at all is impressive, given that the energy of the LUMO ${ }_{\text {carbene }}$ for siloxy carbenes is considerably higher due to interaction of the oxygen atom's non-bonding valence electrons with the unoccupied $2 \mathrm{p}$ carbene orbital. ${ }^{1 \mathrm{~b}}$

The $[2+1]$-photocycloaddition with other less activated alkenes was next considered. Styrene derivative $8 \mathrm{r}$ was prepared via alkylation of the acyl silane with cinnamyl bromide and visible light irradiation $(427 \mathrm{~nm}$ LED, 40W) afforded cyclopropanol 10r in excellent yield (89\%). A cyclohexyl derived olefin tether was also installed which readily underwent cyclopropanation to afford spirocyclic derivative 10p (75\%) generating two new ring systems and contiguous quaternary carbon centres (Scheme 2).

Further investigations into variation of the alkene substituents revealed that phosphonate $(10 \mathrm{q}, 83 \%)$ and amide (10r, $77 \%)$ derived cyclopropane frameworks were readily accessible via the photocycloaddition of nucleophilic carbenes and that tri-substituted alkenes could also be employed to yield penta-substituted cyclopropanes 10s (79\%) and 10t (92\%).

The alkylation of phenol derived acyl silanes with a $1: 1(E) /(Z)$ mixture of 4-bromobut-2-enenitrile enabled us to gain additional insight into the reaction process as the $(E)$ - and $(Z)$-alkenyl acyl silanes were readily separable. Irradiation of each of these substrates $(427 \mathrm{~nm}$ LED, $40 \mathrm{~W})$ resulted in rapid $[2+1]$-cycloaddition with the $(E)$-alkene leading to exclusive formation of the exo-isomer $10 \mathrm{u}$ while the $(Z)$-alkene afforded the endo-isomer as the major product 10v (Scheme 2b).

We explored the opportunity to access azabicyclo[4.1.0]heptanes (Scheme 2c). The ortho-sulfonamido acyl silane derivatives were readily alkylated using various bromocrotonate derivatives with subsequent visible light irradiation (427 nm LED, 40W) producing a series of azabicyclo[4.1.0] heptanes (10w-10ag, Scheme 2c). These cyclopropane adducts were readily identified by ${ }^{1} \mathrm{H}$ NMR analysis from the distinctive cyclopropane $\mathrm{C}-\mathrm{H}$ resonances at $\delta=2.60 \mathrm{ppm}$ and $\delta=1.30 \mathrm{ppm}(J=5.6$ $\mathrm{Hz}$ ). Variations within the silyl group, aryl ring and alkene substituents were well tolerated to afford tetra- or penta- substituted cyclopropanes using only visible-light irradiation. The structure and configuration of azabicyclo[4.1.0] heptane was again confirmed via X-ray crystallographic analysis of 10ab (CCDC 2121949) and 10w (CCDC 2121947). ${ }^{17}$ Furthermore, the use of the $1: 1(E) /(Z)$ mixture of 4-bromobut-2enenitrile afforded access to both the endo and exoisomers of the cyanoderived cyclopropane derivatives $10 \mathrm{af}$ and 10ag.

During investigations into the cyclopropanation of less activated alkenes, up to $20 \%$ conversion of the acyl silane to the dihydrobenzofuran product arising from $\mathrm{C}-\mathrm{H}$ insertion of the carbene into the allylic $\mathrm{CH}_{2}$ moiety was observed via NMR analysis. A related transformation involving $\mathrm{C}-\mathrm{H}$ insertion of thermally generated siloxy carbenes $\left(250^{\circ} \mathrm{C}\right.$, microwave irradiation) to afford 2-phenyldihydrobenzofurans 13 was reported by the Dong group in 2009 with the cis-diastereoisomer formed as the major product (Scheme 3a). ${ }^{18}$ Supported by computational analysis, the Wang group proposed that this thermal carbene insertion process proceeded via an excited singlet carbene intermediate that 

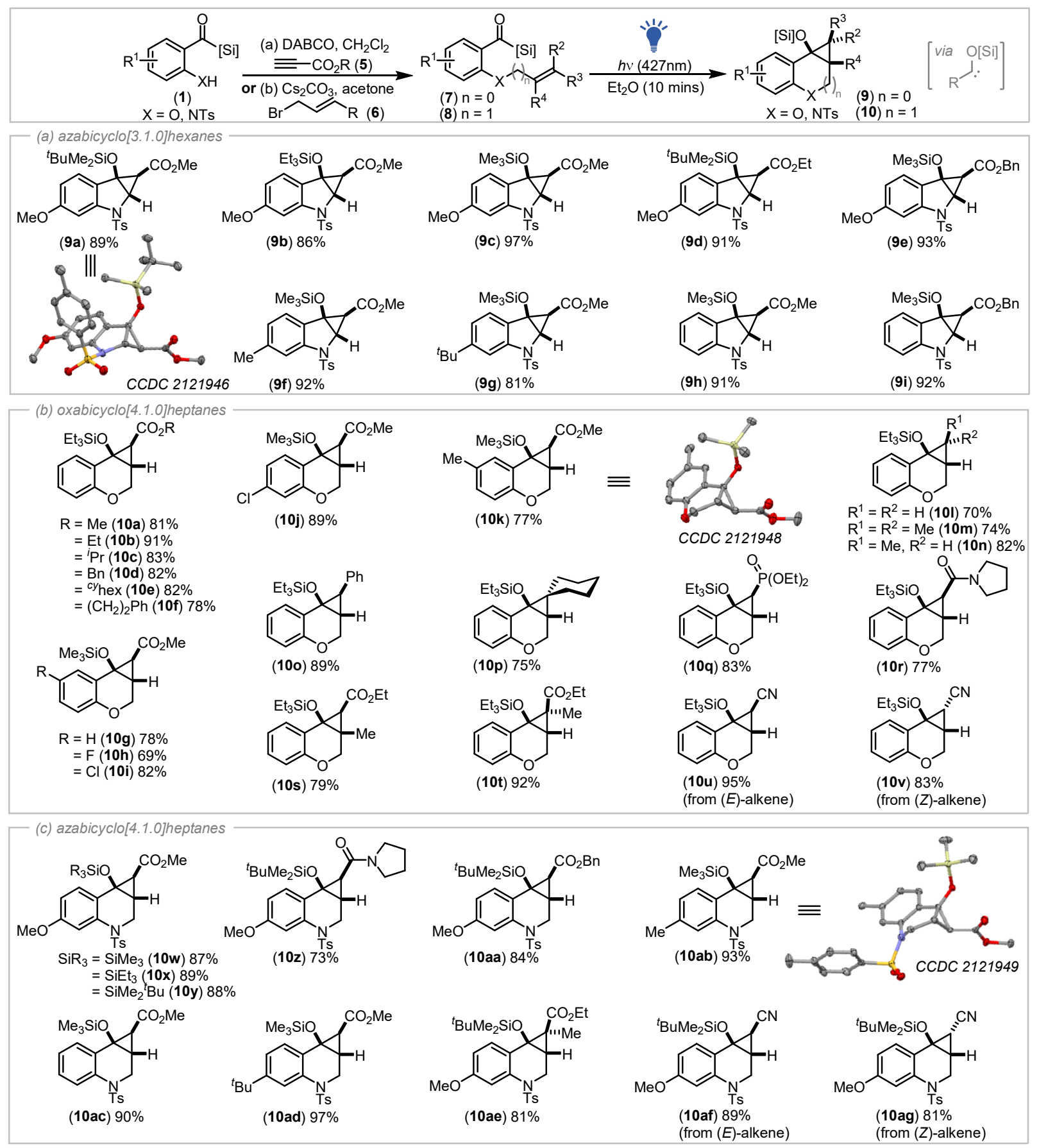

Scheme 2. A novel photochemical [2+1]-cycloaddition of nucleophilic carbenes was developed to access to a series of cyclopropyl-fused heterocyclic scaffolds. Crystal structures of $9 \mathrm{a}$ (CCDC 2121946), 10k (CCDC 2121948) and 10ab (CCDC 2121949) depicted at 50\% probability (hydrogen atoms omitted for clarity): carbon (grey), oxygen (red), nitrogen (blue), sulfur (orange) and silicon (yellow).

abstracted a hydrogen atom from the proximal benzylic position to afford a diradical that underwent diradical coupling to afford dihydrofuran $13 .{ }^{19}$

Building on our observation that photochemically generated siloxy carbenes could also undergo $\mathrm{C}-\mathrm{H}$ insertion, we were intrigued by the possibility of replicating the process reported by Dong with visible light irradiation at ambient temperature. To explore this, we prepared benzyloxy aroyl silane 11 and following irradiation with visible light (427nm LED, 40W, 16h), we successfully isolated the corresponding 2phenyldihydrofuran 12 in $63 \%$ yield (Scheme $3 a$ ). Intriguingly, the major product formed via the photochemical reaction was the transdiastereomer in a ratio of 10:1, inferring that the photochemical process occurs via an alternative mechanism to the thermal process reported by
Dong, proposedly via $\mathrm{C}-\mathrm{H}$ insertion of ground state singlet carbene, an observation currently under further investigation within our group.

As is the case for donor-acceptor cyclopropanes, ring opening and expansion protocols exploiting the inherent ring strain of bicyclo[3.1.0] hexane and bicyclo[4.1.0] heptane derivatives have also been developed to access polycyclic scaffolds. ${ }^{20}$ To this end, we demonstrated that both aza- and oxa-bicyclo[4.1.0]heptanes readily underwent ring expansion reaction with hydrazine to afford unique heterocyclic frameworks (Scheme $3 \mathrm{~b}$ ). Due to the fast and catalyst-free nature of the $[2+1]$-photocycloaddition process described herein, development of additional reaction telescoping strategies to rapidly generate molecular complexity are under investigation. 

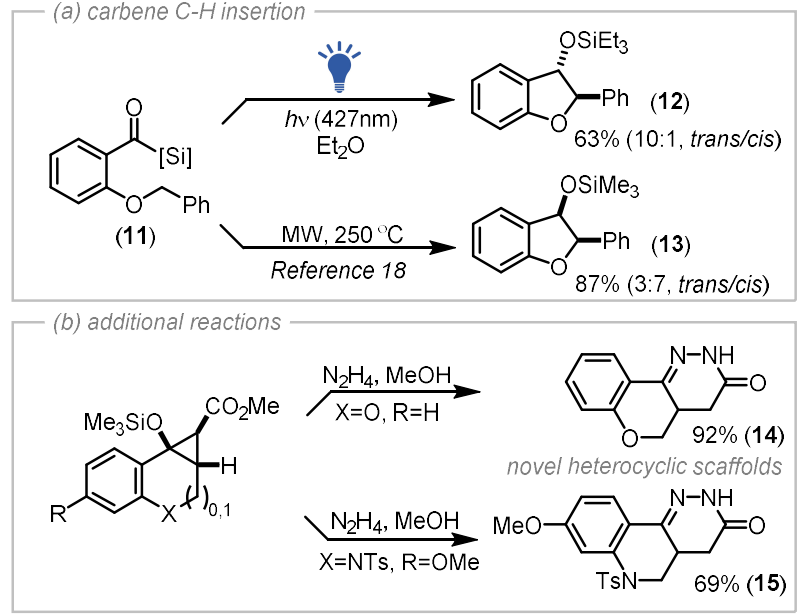

Scheme 3. (a) A highly diastereoselective $\mathrm{C}-\mathrm{H}$ insertion process of visible-light induced carbenes was also discovered; (b) Ring expansion processes via reaction with hydrazine afforded novel heterocycles.

Mechanistically, the photochemical cyclopropanation of nucleophilic carbenes described herein could be occurring via either a stepwise or concerted pathway (Scheme 4a). For the less activated alkenes which required longer reaction times (up to 2 hours), the concerted pathway is most plausible, however for electron deficient alkenes, both a concerted and a stepwise process (involving initial Michael addition of the nucleophilic carbene to the electron deficient alkene followed by ring closure via addition of the resultant enolate to the oxonium ion) to afford the thermodynamically favoured exo-isomer can be envisaged.

Key insights into the mechanism of this photochemical $[2+1]$ cycloaddition were provided by the cyano-derived alkene whereby the $(E)$-alkene exclusively afforded the exo-isomer, and the ( $Z$ )-alkene produced the endo-isomer as the major product, inferring that the reaction occurs in a concerted and highly stereospecific fashion (Scheme $4 a)$. Intriguingly, it was observed that in deuterated chloroform the kinetically favoured endo-product $10 \mathrm{ag}$ produced from the $(Z)$-cyanoalkene isomerised over time to the thermodynamically favoured exoisomer 10af (via ring opening/closing - Scheme 4a).

During initial studies into the cyclopropanation of salicylaldehyde derived acyl silanes, an electron deficient olefin was installed via the DABCO catalysed reaction of the phenolic-OH with methyl propiolate. ${ }^{16}$ Visible-light irradiation ( $427 \mathrm{~nm} \mathrm{LED}, 40 \mathrm{~W}$ ) of a solution of diethyl ether containing acyl silane $7 \mathrm{j}$ led to a colour change from bright yellow to colourless after only 10 minutes. Analysis of the reaction mixture by NMR spectroscopy indicated that no cyclopropane product was present and instead complete conversion of the acyl silane to a new product had occurred. Further analysis revealed the structure of the product to be that of the silyl enol ether derived pyran 16a (Scheme 4b). Formation of this product occurs via a photochemical cascade reaction initiated by rapid cyclopropanation of the carbene with the proximal alkene, followed by ring opening that generates an enolate intermediate that drives a retrooxa-Michael reaction to afford a phenolate that undergoes Michael addition onto the activated acceptor to afford silyl enol ether $16 a^{21}$ Subsequent hydrolysis of silyl enol ether 16 a readily afforded chromanone 17a (Scheme 4b).

Acyl silane 7k prepared from ethyl propiolate also underwent the photochemical cascade process to afford $16 \mathrm{~b}$ and following hydrolysis, $17 \mathrm{~b}$. For the photochemical cascade reaction outlined in Scheme $4 \mathrm{~b}$, it could be considered that the first step of this process is Michael-type addition of the nucleophilic carbene to the alkene rather than cyclopropanation. However, gradual isomerisation of the corresponding tosylamide cyclopropane $9 c$ to the quinoline $16 c$ in deuterated chloroform and subsequent hydrolysis to afford $17 \mathrm{c}$ was observed by NMR analysis. This isomerisation proposedly occurs via the same ringopening, retro-Michael/Michael addition process, inferring that the first step of the rapid photochemical cascade reaction is indeed cyclopropanation (Scheme 4b).

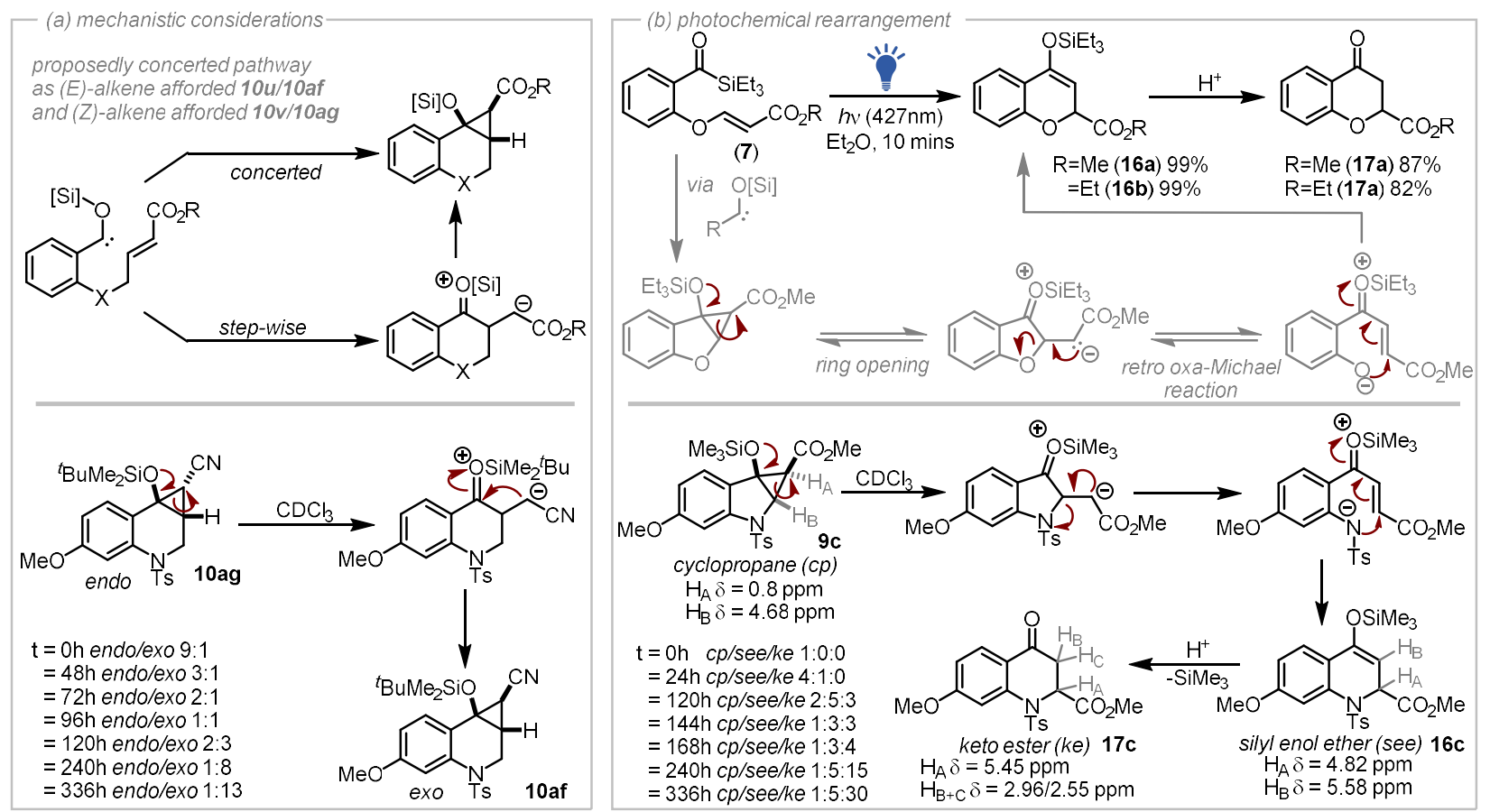

Scheme 3. (a) The photochemical [2+1]-cycloaddition of nucleophilic carbenes is observed to proceed in a highly stereospecific manner via a concerted mechanism. The gradual isomerisation of the endo-isomer to the exo-isomer also occurred. (b) A unique photochemical cascade reaction involving cyclopropanation, ring opening, retro-Michael, and Michael reaction to afford new heterocyclic derivatives was also discovered. 
In summary, we have discovered that visible light induced nucleophilic carbene intermediates undergo rapid [2+1]-cycloaddition with olefins to afford valuable bicyclo[3.1.0]hexane and bicyclo[4.1.0]heptane scaffolds. Advantageously, this highly stereospecific reaction requires only visible light irradiation avoiding the requirement for exogenous additives and (photo)catalysts to afford a unique class of silicon-derived donor-acceptor cyclopropanes.

Owing to the inherent nucleophilicity of the carbene intermediates, the reaction is compatible with electron deficient alkenes and less activated olefins including a cyclohexane derived alkene that produced a spirocyclic scaffold. Investigations into the reactivity of visible light induced nucleophilic carbene intermediates also unveiled a novel C-H insertion process to afford 2-phenyldihydrofurans with high diastereoselectivity, and a unique photochemical cascade reaction involving a cyclopropanation/retro-Michael/Michael process.

Overall, the discoveries reported herein are anticipated to pave the way for the development of new synthetic transformations that capitalize on the ability of nucleophilic carbene intermediates to participate in synthetically useful $[2+1]$-photocycloaddition processes.

\section{Acknowledgements}

DLP acknowledges the support of the Australian Research Council (DE200100949). AP acknowledges the University of Melbourne and CSIRO for the joint Establishment Grant and the Australian Research Council (IC1701000020). Dr Carol Hua (X-Ray Crystallography, University of Melbourne) is thanked for assistance with this project.

\section{References}

1. (a) H.-U. Reissig and R. Zimmer, Chem. Rev., 2003, 103, 1151-1196; (b) T. F. Schneider, J. Kaschel and D. B. Werz, Angew. Chem., Int. Ed., 2014, 53, 5504-5523; (c) K. Ghosh and S. Das, Org. Biomol. Chem., 2021, 19, 965-982; (d) D. B. Werz and A. T. Biju, Angew. Chem., Int. Ed., 2020, 59, 3385-3398; (e) T. R. McDonald, L. R. Mills, M. S. West and S. A. L. Rousseaux, Chem. Rev., 2021, 121, 3-79; (f) L. R. Mills and S. A. L. Rousseaux, Eur. J. Org. Chem., 2019, 2019, 8-26; (g) O. G. Kulinkovich, Chem. Rev., 2003, 103, 2597-2632; (h) A. Nikolaev and A. Orellana, Synthesis, 2016, 48, 1741-1768.

2. (a) G. A. Chesnokov and K. Gademann, J. Am. Chem. Soc., 2021, 143, 1408314088; (b) M.-Y. Lyu, Z. Zhong, V. K.-Y. Lo, H. N. C. Wong and X.-S. Peng, Angew. Chem., Int. Ed., 2020, 59, 19929-19933; (c) Y. H. Jin Wenbing, Tang Gongli, Chin. J. Org. Chem., 2018, 38, 2324-2334.

3. (a) T. T. Talele, J. Med. Chem., 2016, 59, 8712-8756; (b) S. J. Chawner, M. J. Cases-Thomas and J. A. Bull, Eur. J. Org. Chem., 2017, 2017, 5015-5024; (c) R. D. Taylor, M. MacCoss and A. D. G. Lawson, J. Med. Chem., 2014, 57, 5845-5859; (d) J. Salaün, in Small Ring Compounds in Organic Synthesis VI, ed. A. de Meijere, Springer Berlin Heidelberg, Berlin, Heidelberg, 2000, DOI: 10.1007/3-540-48255-5_1, pp. 1-67.

4. M. M. Hamilton, F. Mseeh, T. J. McAfoos, P. G. Leonard, N. J. Reyna, A. L. Harris, A. Xu, M. Han, M. J. Soth, B. Czako, J. P. Theroff, P. K. Mandal, J. P. Burke, B. Virgin-Downey, A. Petrocchi, D. Pfaffinger, N. E. Rogers, C. A. Parker, S. S. Yu, Y. Jiang, S. Krapp, A. Lammens, G. Trevitt, M. R. Tremblay, K. Mikule, K. Wilcoxen, J. B. Cross, P. Jones, J. R. Marszalek and R. T. Lewis, J. Med. Chem., 2021, 64, 11302-11329.

5. (a) P. Helquist, in Comprehensive Organic Synthesis, eds. B. M. Trost and I. Fleming, Pergamon, Oxford, 1991, DOI: https://doi.org/10.1016/B978-008-052349-1.00113-X, pp. 951-997; (b) H. E. Simmons and R. D. Smith, J. Am. Chem. Soc., 1958, 80, 5323-5324; (c) A.-H. Li, L.-X. Dai and V. K. Aggarwal, Chem. Rev., 1997, 97, 2341-2372.

6. (a) W. Wu, Z. Lin and H. Jiang, Org. Biomol. Chem., 2018, 16, 7315-7329; (b) C. Ebner and E. M. Carreira, Chem. Rev., 2017, 117, 11651-11679; (c) H. Lebel, J.-F. Marcoux, C. Molinaro and A. B. Charette, Chem. Rev., 2003, 103, 977-1050; (d) H. M. L. Davies and E. G. Antoulinakis, 2004; (e) G. Bertrand, in Reactive Intermediate Chemistry, eds. R. A. Moss, M. S. Platz and M. Jones Jr, John Wiley \& Sons, Inc. , Hoboken, NJ, 2004, ch. 8.

7. (a) E. M. D. Allouche and A. B. Charette, Synthesis, 2019, 51, 3947-3963; (b) A. Dasgupta, R. Babaahmadi, B. Slater, B. F. Yates, A. Ariafard and R. L. Melen, Chem, 2020, 6, 2364-2381; (c) S. J. Hedley, D. L. Ventura, P. M. Dominiak, C. L. Nygren and H. M. L. Davies, J. Org. Chem., 2006, 71, 5349-5356; (d) D. Marcoux, S. Azzi and A. B. Charette, J. Am. Chem. Soc., 2009, 131, 6970-
6972; (e) M. Delgado-Rebollo, A. Prieto and P. J. Pérez, ChemCatChem, 2014, 6, 2047-2052; (f) C. Deng, H.-K. Liu, Z.-B. Zheng, L. Wang, X. Yu, W. Zhang and Y. Tang, Org. Lett., 2017, 19, 5717-5719; (g) H. Xu, Y.-P. Li, Y. Cai, G.-P. Wang, S.-F. Zhu and Q.-L. Zhou, J. Am. Chem. Soc., 2017, 139, 7697-7700; (h) H. Wang, D. M. Guptill, A. Varela-Alvarez, D. G. Musaev and H. M. L. Davies, Chem. Sci., 2013, 4, 2844-2850; (i) C. G. Hamaker, G. A. Mirafzal and L. K. Woo, Organometallics, 2001, 20, 5171-5176; (j) Y. Chen, J. V. Ruppel and X. P. Zhang, J. Am. Chem. Soc., 2007, 129, 12074-12075.

8. (a) M. Tavakolian and M. Hosseini-Sarvari, ACS Sustain. Chem. Eng., 2021, 9, 4296-4323; (b) Z. Yang, Y. Liu, K. Cao, X. Zhang, H. Jiang and J. Li, Beil.J. Org. Chem., 2021, 17, 771-799.

9. A. G. Herraiz and M. G. Suero, Chem. Sci., 2019, 10, 9374-9379.

10. (a) Y. Guo, C. Empel, C. Pei, I. Atodiresei, T. Fallon and R. M. Koenigs, Org. Lett., 2020, 22, 5126-5130; (b) S. Jana, F. Li, C. Empel, D. Verspeek, P. Aseeva and R. M. Koenigs, Chem. - Eur. J., 2020, 26, 2586-2591; (c) Z. Yang, M. L. Stivanin, I. D. Jurberg and R. M. Koenigs, Chem. Soc. Rev, 2020, 49, 68336847.

11. (a) D. L. Priebbenow, J. Org. Chem., 2019, 84, 11813-11822; (b) D. L. Priebbenow, $A d v$. Synth. Catal, 2020, 362, 1927-1946; (c) D. L. Priebbenow, R. L. Pilkington, K. N. Hearn and A. Polyzos, Org. Lett., 2021, 23, 2783-2789; (d) P. Becker, R. Pirwerdjan and C. Bolm, Angew. Chem., Int. Ed., 2015, 54, 15493-15496; (e) P. Becker, D. L. Priebbenow, R. Pirwerdjan and C. Bolm, Angew. Chem., Int. Ed., 2014, 53, 269-271; (f) P. Becker, D. L. Priebbenow, H.-J. Zhang, R. Pirwerdjan and C. Bolm, J. Org. Chem., 2014, 79, 814-817; (g) H.-J. Zhang, P. Becker, H. Huang, R. Pirwerdjan, F.-F. Pan and C. Bolm, Adv. Synth. Catal., 2012, 354, 2157-2161; (h) J.-H. Ye, P. Bellotti, T. O. Paulisch, C. G. Daniliuc and F. Glorius, Angew. Chem., Int. Ed., 2021, 60, 13671-13676; (i) J.-H. Ye, L. Quach, T. Paulisch and F. Glorius, J. Am. Chem. Soc., 2019, 141, 16227-16231; (j) K. Ishida, F. Tobita and H. Kusama, Chem. - Eur. J., 2018, 24, 543-546; (k) K. Ishida, H. Yamazaki, C. Hagiwara, M. Abe and H. Kusama, Chem. - Eur. J., 2020, 26, 1249-1253; (1) K. Ito, H. Tamashima, N. Iwasawa and H. Kusama, J. Am. Chem. Soc., 2011, 133, 37163719; (m) J. Reimler and A. Studer, Chem. - Eur. J., 2021, 27, 15392-15395; (n) C. Stuckhardt, M. Wissing and A. Studer, Angew. Chem., Int. Ed., 2021, 60, 18605-18611; (o) Z. Fan, Y. Yi, S. Chen and C. Xi, Org. Lett., 2021, 23, 2303-2307; (p) L. Ma, Y. Yu, L. Xin, L. Zhu, J. Xia, P. Ou and X. Huang, $A d v$. Synth. Catal., 2021, 363, 2573-2577.

12. (a) J. C. Dalton and R. A. Bourque, J. Am. Chem. Soc., 1981, 103, 699-700; (b) A. G. Brook, H. W. Kucera and R. Pearce, Can. J. Chem., 1971, 49, 16181621.

13. (a) R. A. Moss, M. Wlostowski, S. Shen, K. Krogh-Jespersen and A. Matro, J. Am. Chem. Soc., 1988, 110, 4443-4444; (b) R. A. Moss, S. Shen, L. M. Hadel, G. Kmiecik-Lawrynowicz, J. Wlostowska and K. Krogh-Jespersen, J. Am. Chem. Soc., 1987, 109, 4341-4349; (c) A. Igau, A. Baceiredo, G. Trinquier and G. Bertrand, Angew. Chem., Int. Ed., 1989, 28, 621-622; (d) S. GoumriMagnet, T. Kato, H. Gornitzka, A. Baceiredo and G. Bertrand, J. Am. Chem. Soc., 2000, 122, 4464-4470. (e) The reaction of $N$-heterocyclic carbenes (NHCs) with olefins does not afford cyclopropanes but methylene adducts, see: D. Enders, K. Breuer, G. Raabe, J. Runsink, J. H. Teles, J.-P. Melder, K. Ebel and S. Brode, Angew. Chem., Int. Ed., 1995, 34, 1021-1023;

14. (a) A. E. Keating, S. R. Merrigan, D. A. Singleton and K. N. Houk, J. Am. Chem. Soc., 1999, 121, 3933-3938; (b) N. G. Rondan, K. N. Houk and R. A. Moss, J. Am. Chem. Soc., 1980, 102, 1770-1776; (c) J.-L. Mieusset, M. Abraham and U. H. Brinker, J. Am. Chem. Soc., 2008, 130, 14634-14639; (d) B. Lecea, M. Ayerbe, A. Arrieta, F. P. Cossío, V. Branchadell, R. M. Ortuño and A. Baceiredo, J. Org. Chem., 2007, 72, 357-366.

15. Secondary orbital interactions between the vacant carbene 2 p-orbital

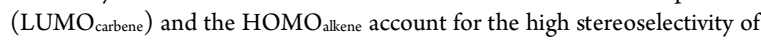
nucleophilic carbene cyclopropanation processes. .

16. M.-J. Fan, G.-Q. Li and Y.-M. Liang, Tetrahedron, 2006, 62, 6782-6791.

17. Refer to the Supporting Information for additional details.

18. Z. Shen and V. M. Dong, Angew. Chem., Int. Ed., 2009, 48, 784-786.

19. D. Cai, M. Wang, J. Wang and W. Duan, J. Phys. Org. Chem., 2012, 25, 400408.

20. (a) N. Wurzer, U. Klimczak, T. Babl, S. Fischer, R. A. Angnes, D. Kreutzer, A. Pattanaik, J. Rehbein and O. Reiser, ACS Catal,, 2021, DOI: 10.1021/acscatal.1c02564, 12019-12028; (b) M. Yu and B. L. Pagenkopf, Org. Lett., 2003, 5, 5099-5101; (c) M. Yu and B. L. Pagenkopf, J. Am. Chem. Soc., 2003, 125, 8122-8123; (d) D. Gladow and H.-U. Reissig, Helv. Chim. Acta, 2012, 95, 1818-1830; (e) J. Saadi, C. Bentz, K. Redies, D. Lentz, R. Zimmer and H.-U. Reissig, Beil.J. Org. Chem., 2016, 12, 1236-1242.

21. L.-W. Ye, X.-L. Sun, C.-Y. Zhu and Y. Tang, Org. Lett., 2006, 8, 3853-3856. 